\title{
La mutagenèse insertionnelle chez la souris
}

La mutagenèse insertionnelle permet tout à la fois d'altérer la fonction d'un gène et de détecter simplement le gène ainsi modifié. Les rétrovirus ont l'avantage, par rapport aux autres techniques, de s'insérer sans entraîner de remaniements importants de l'ADN de la cellule hôte. Les chercheurs ont donc là en main un outil puissant pour identifier des gènes intervenant dans le développement embryonnaire.

\section{Jean-Jacques Panthier Hubert Condamine}

\section{ADRESSE}

J.-J. Panthier : chargé de recherche à l'Institut Pasteur. H. Condamine: professeur à l'Uni- versité Paris VII. Unité de génétique cellu- des radiations ou par des mutagènes

versité Paris VII. Unité de génétique cellu- Institut Pasteur, 25, rue du Docteur- des radiations ou par des mutagènes chimiques pour étudier les méca- nismes moléculaires qui gouvernent le développement embryonnaire chez les mammifères. tions, spontanées induites par des radiations ionisantes, ont été identifiées chez la souris depuis environ 50 ans. Certaines de ces mutations ont fait l'objet de très longues recherches; parmi ces mutations désormais «classiques » de la souris, on peut citer la série des mutations du locus albinos, les mutations $W$, pléiotropes, qui affectent à la fois l'hématopoïèse, la fertilité et la coloration du pelage, et les haplotypes $T / t$, qui touchent notamment à la fertilité des spermatozoïdes [1]. Pour chacune de ces mutations le phénotype muté a été très précisément caractérisé et la mutation a été localisée sur l'un des 21 chromosomes de la souris. Cependant dans aucun de ces cas il n'a encore été possible d'analyser au niveau moléculaire le ou les gènes mutés et/ou d'identifier le produit de la transcription (l'ARN) ou de la traduction (la protéine) responsable du phénotype muté. Cet échec explique le faible espoir mis dans les mutants spontanés ou induits par

\section{La mutagenèse insertionnelle}

De nombreuses mutations spontanées des procaryotes, de la levure, de la drosophile et du maïs sont le résultat de l'insertion d'un fragment d'ADN, sous la forme d'un élément transposable, à l'intérieur ou au voisinage d'un gène. Le phénotype muté résulte alors soit de l'inactivation (partielle ou totale) du gène cellulaire, soit inversement de son activation. Une telle mutation est dite «mutation insertionnelle». Le très grand intérêt de ce type de mutation est que le gène interrompu est désormais « marqué » par les séquences d'ADN de l'élément transposable. Aussi l'élément transposable peut-il être utilisé comme sonde moléculaire pour isoler et cloner les séquences d'ADN qui entourent le site d'insertion, et qui a priori renferment le gène affecté.

Il est raisonnable de penser que, chez la souris, l'insertion d'un fragment d'ADN peut également provoquer 


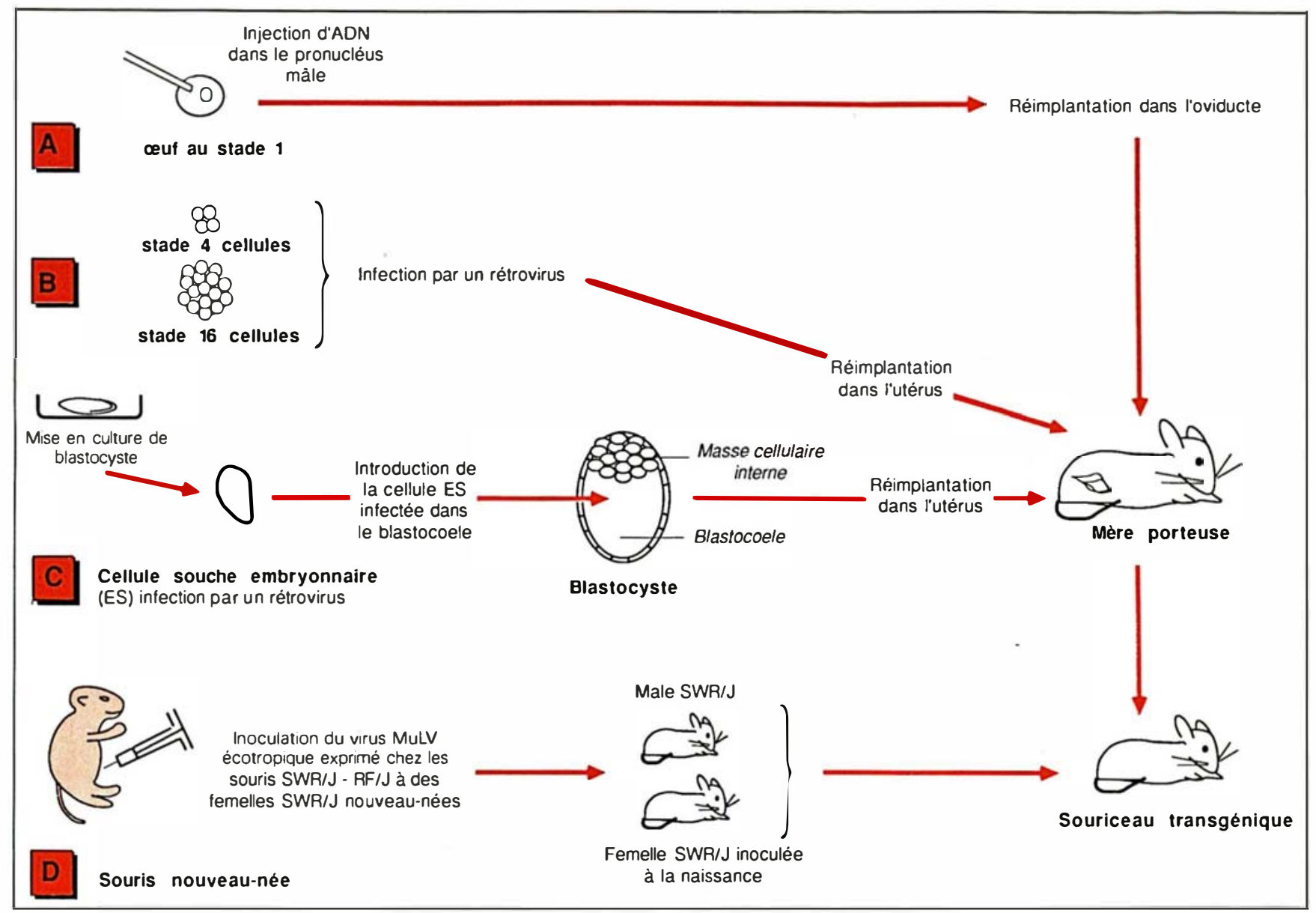

Figure 1. Quatre méthodes couramment utilisées pour introduire de I'ADN dans le génome de la souris. A. la micro-injection d'ADN dans le pronucléus mâle d'un œuf fécondé $[5,6]$; B. l'infection d'un embryon précoce par un rétrovirus [11]; C. l'infection, par un rétrovirus [13], de cellules embryonnaires souches, dérivées de la mise en culture d'un blastocyste. Ces trois méthodes nécessitent de prélever des œufs ou des embryons de souris, qui sont manipulés in vitro avant d'être réintroduits dans l'oviducte $(A)$ ou dans l'utérus $(B$ et $C$ ) d'une mère porteuse qui mettra au monde les souriceaux transgéniques; D. l'inoculation à des femelles SWR/J nouveau-nées du virus MuLV écotropique qui est exprimé chez les souris hybrides SWR/J-RF/J[29]. Cette dernière méthode n'implique pas de manipulation d'œufs ou d'embryons, l'infection rétrovirale des cellules germinales se produit in vivo chez la femelle inoculée.

des anomalies dans l'expression d'un gène. Si l'insertion de cet ADN a lieu dans une cellule de la lignée germinale (en pratique un gamète, l'œuf, un blastomère ou une cellule embryonnaire souche), l'ADN inséré (et l'anomalie qu'il occasionne) sera, tout comme les séquences chromosomiques qui l'entourent, transmis à la descendance. On aura ainsi induit une mutation. Pour une revue récente de cette question, on pourra consulter Gridley, et al. [2]. D'autre part deux articles récents de médecine/sciences, consacrés aux animaux $\mathrm{m} / \mathrm{s} n^{\circ} 9$ vol. 4 , novembre 88 transgéniques, complètent les données rassemblées dans le présent article $[3,4]$.

\section{Les techniques d'insertion d'ADN dans le génome de la souris}

On ne connaît pas à ce jour d'élément transposable chez la souris; on peut, en revanche, fort bien introduire dans le génome de la lignée germinale des fragments d'ADN étrangers. Les souris qui portent ces fragments d'ADN étrangers sont dites «souris transgéniques» tandis que le fragment d'ADN introduit est appelé le «transgène ».

Plusieurs méthodes permettent de réaliser cette insertion (figure 1). La plus utilisée est la micro-injection directe d'une molécule d'ADN dans l'œuf: lorsqu'on injecte des molécules linéaires d'ADN dans le pronucléus mâle d'un œuf fécondé, on observe qu'environ $25 \%$ des 'souris qui naissent de ces œufs manipulés portent, intégrées dans leur génome, une ou plusieurs copies de l'ADN injecté $[5,6]$. Le mécanisme de l'in- 
RÉFÉRENCES

1. Green MC. Genetic variants and strains of the laboratory mouse. Stuttgart: Gustav Fischer Verlag, 1981.

2. Gridley $\mathrm{T}$, Soriano $\mathrm{P}$, Jaenisch R. Insertional mutagenesis in mice. Trends Genet 1987 ; $3: 162-6$.

3. Babinet C, Morello D. Animaux transgéniques: une voie nouvelle pour l'étude du développement. médecine/sciences $1986 ; 2$ : 253-9.

4. Kahn A. Créations de modèles animaux de maladies humaines héréditaires. médecinel sciences $1987 ; 3: 368-9$.

5. Gordon JW, Scangos GA, Plotkin DJ, Barbosa JA, Ruddle FH. Genetic transformation of mouse embryos by microinjection of purified DNA. Proc Natl Acad Sci USA 1980; 77 : 7380-4.

6. Palmiter RD, Brinster RL. (1986) Germline transformation of mice. Ann Rev Genet 1986 ; 20 : 465-99.

7. Woychik RP, Stewart TA, Davis LG D'Eustachio P, Leder P. An inherited limb deformity created by insertional mutagenesis in a transgenic mouse. Nature $1985 ; 318$ : 36 40.

8. Palmiter RP, Wilkie TM, Chen HY, Brinster RL. Transmission distortion and mosaicism in an unusual transgenic mouse pedigree. Cell 1983 ; 36 : 869-77.

9. Covarrubias L, Nishida Y, Mintz B. (1986) Early postimplantation embryo lethality due to DNA rearrangements in a transgenic mouse strain. Proc Natl Acad Sci. USA 1986 ; $83: 6020-4$

10. Overbeek PA, Lai SP, Van Quill KR, Westphal H. Tissue-specific expression in transgenic mice of a fused gene containing RSV terminal sequences. Science 1986; 231 : 1574-7.

11. Jähner D, Jaenisch R. Integration of Moloney leukaemia virus into the germ line of mice : correlation between site of integration and virus activation. Nature $1980 ; 287$ : 456-8.

12. Jaenisch R. Retroviruses and embryogenesis : microinjection of Moloney leukemia virus into midgestation mouse embryos. Cell $1980 ; 19$ : 181-8.

13. Robertson E, Bradley A, Kuehn M Evans M. Germline transmission of genes introduced into cultured pluripotential cells by retroviral vector. Nature $1986 ; 323: 445-8$.

14. Jaenisch R, Mintz B. (1974) Simian virus 40 sequences in DNA of healthy adult mice derived from preimplantation blastocysts injected with viral DNA. Proc Natl Acad Sci tégration est inconnu, mais l'analyse moléculaire de quelques régions comprenant l'ADN étranger intégré dans un chromosome de la souris a clairement montré que des délétions, des duplications et des translocations des séquences chromosomiques ont lieu lors de l'intégration. On a même observé que certains sites d'intégration contiennent de petits fragments d'ADN qui n'étaient présents ni dans la molécule d'ADN injectée ni au site d'intégration avant que cette dernière se produise. L'ADN étranger est ensuite, le plus souvent, transmis de génération en génération sans le moindre signe de réarrangement ultérieur.

Plusieurs milliers de souris ayant acquis dans leur génome des fragments d'ADN étranger ont été produites par cette méthode. On a observé qu'environ $7 \%$ des souris transgéniques, obtenues par microinjection d'ADN, portent une mutation entraînant à l'état homozygote un phénotype particulier. Certaines de ces mutations sont du plus grand intérêt. Ainsi la mutation $\mathrm{ld}^{\text {Hd }}$ qui affecte le développement des membres, occasionnée par l'insertion d'un transgène sur le chromosome 2 au niveau d'un gène ld (pour limb deformity) déjà repéré par plusieurs mutations récessives : chez l'homozygote $\mathrm{ld}^{\mathrm{Hd}} / \mathrm{ld}^{\mathrm{Hd}}$, le radius et le cubitus, de même que le tibia et le péroné, sont soudés ; en outre, plusieurs os des doigts sont fusionnés ou manquants. Le transgène ainsi que les séquences voisines ont été isolés par clonage moléculaire, et il a été montré qu'environ un kilobase de séquence d'ADN cellulaire a été perdu lors de l'intégration [7]. On peut également citer une mutation qui affecte la transmission à la descendance : le transgène baptisé $M y K$ 103 , qui est localisé sur le chromosome 6 de la souris, est transmis normalement (c'est-à-dire de façon mendélienne) lorsqu'il est porté par une femelle; en revanche, lorsqu'il est porté par un mâle il n'est pas transmis à la descendance [8]. Là aussi la région où s'est inséré le transgène a été clonée, et l'on a observé qu'une duplication d'un fragment de cinq kilobases d'ADN chromosomique s'était produite lors de l'intégration. Dans aucun de ces cas il n'a été possible d'établir une relation de cause à effet entre l'avènement de la délétion dans le premier cas, de la duplication dans l'autre, et les phénotypes mutés observés. (Pour d'autres exemples de mutations par injection de séquence dans l'ADN de l'œuf, voir les références [9] et [1.0].) Cela illustre les difficultés rencontrées dans l'analyse des mutants insertionnels obtenus à la suite de la micro-injection d'ADN. En effet l'intégration s'accompagne de remaniements parfois très importants et il devient impossible d'identifier le gène dont le fonctionnement est perturbé. Ces problèmes ne devraient pas être rencontrés lorsque les mutations résultent de l'insertion de génomes viraux : les virus ont développé des systèmes d'intégration efficaces qui n'entraînent que peu de remaniements des séquences d'ADN cellulaire.

Pour obtenir des souris transgéniques pour un génome viral, on expose des embryons de souris à un virus infectieux. Cette infection est possible à différents stades de l'embryogenèse: in vitro au stade 4-16 cellules [11], ou par injection directe in vivo sur des embryons au jour 8 de la gestation [12]. Dans les cas les plus favorables $10 \%$ des souris qui résultent de ces manipulations acquièrent dans leurs chromosomes une ou plusieurs copies du génome viral, à raison d'une copie par site d'intégration. On peut obtenir le même résultat en utilisant des lignées de cellules embryonnaires provenant de la culture in vitro d'embryons pris au stade blastocyste (cellules dites ES, pour Embryonic stem cells). Les cellules ES sont replacées, après l'infection par le virus, dans la cavité d'un blastocyste de souris où elles contribuent aux lignages somatique et germinal de l'embryon qui se développe après réimplantation dans l'utérus d'une mère porteuse [13]

Dans le cas des souris transgéniques obtenues grâce à ces virus, le transgène correspond au génome du virus lui-même. Ce génome viral peut d'ailleurs être plus ou moins modifié par rapport au génome du virus naturel, selon que l'on a ou non supprimé des séquences virales et/ou inséré des séquences d'ADN étrangères au $v$ irus. Le premier virus uti- 
lisé pour réaliser ce type d'expérience fut le virus simien SV40 [14]. Depuis 1976, les rétrovirus leucémogènes murins lui sont préférés [15].

\section{Les rétrovirus}

leucémogènes de la souris

Jacob Furth a développé il y a plus de 50 ans une lignée de souris consanguines leucémiques : $90 \%$ des souris de cette lignée, la lignée AKR, sont atteintes de lymphome thymique (thymome ou leucémie thymi- de cette maladie, présent dans les extraits acellulaires préparés par Gross, fut rapidement identifié : il s'agit d'un rétrovirus, que l'on retrouve dans les tissus leucémiques des souris AKR

Dans les années 1950 et au début des années 1960, de nombreux autres auteurs isolèrent indépendamment des virus leucémogènes chez la souris. Ces rétrovirus furent baptisés MuLV (pour murine leukemia virus). Certains de ces virus, c'est le cas des virus de Moloney (Mo-

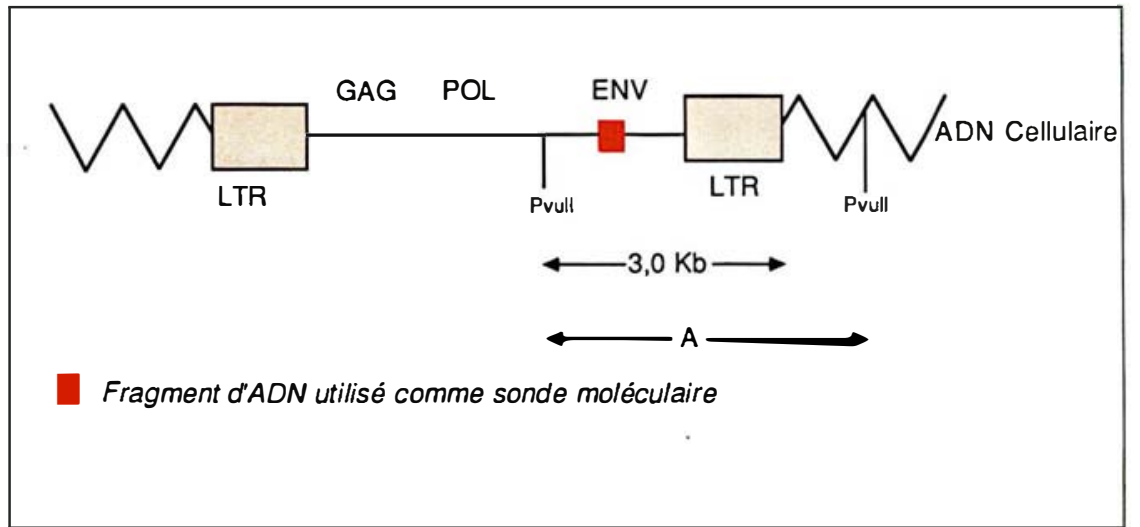

Figure 2. La souris héberge dans ses chromosomes des virus murins leucémogènes (MuLV). Le génome du virus MuLV constitué de ses séquences régulatrices (LTR) entourant les trois gènes viraux (GAG, POL et ENV) est inséré dans I'ADN d'une souris (ligne brisée) sous la forme d'un provirus. Lorsqu'on digère I'ADN de cette souris par l'enzyme Pvull, on produit un fragment $A$, qui hybride avec la sonde EN utilisée et dont la taille est fonction de la distance séparant le site Pvull viral du premier site Pvull rencontré sur I'ADN cellulaire. Ainsi chaque provirus MuLV présent dans le génome de la souris donnera naissance à un fragment unique d'une taille définie. Selon la nature de la sonde ENV utilisée, on peut connaître le contenu en provirus MuLV écotropique [22] et/ou xénotropique [21] d'une souris donnée.

que) à l'âge de 6-10 mois. En revanche, $10 \%$ de ces souris ne développent pas de leucémies, bien qu'elles donnent naissance à des souris qui sont atteintes [à $90 \%$ ] de lymphomes thymiques. En 1951, Ludwig Gross prépare un extrait acellulaire à partir d'une suspension de cellules leucémiques prélevées sur des souris AKR. Il montre que l'inoculation, avec cet extrait, de souris nouveau-nées appartenant à des lignées non leucémiques, provoque l'apparition, dans les six mois suivant l'inoculation, de leucémies généralisées [16]. L'agent responsable $\mathrm{m} / \mathrm{s} n^{\circ} 9$ vol. 4, novembre 88 ce qui signifie qu'il est transmis verticalement de génération en génération, via la lignée germinale. Les virus exogènes, au contraire, sont transmis horizontalement à l'intérieur d'une même génération, par infections successives.

Les virus MuLV ont été classés en trois groupes distincts: (a) les virus «écotropiques », qui pénètrent et se répliquent dans les cellules de souris, mais pas dans les cellules d'autres mammifères; (b) les virus «xénotropiques », qui ont une spécificité d'hôte opposée : ils peuvent infecter une grande variété de cellules de mammifères, mais ne peuvent pas infecter les cellules de souris; (c) les virus « amphotropiques », qui ont les propriétés communes des virus écotropiques et xénotropiques : ils infectent des cellules de souris ainsi que de nombreux autres mammifères. Si ces derniers virus sont absents des lignées consanguines de souris, en revanche, on a pu les isoler à partir de certaines souris sauvages [20].

Les glycoprotéines de l'enveloppe de ces trois classes de virus MuLV sont différentes, interagissant avec des récepteurs membranaires différents de la surface des cellules; ce sont ces glycoprotéines d'enveloppe qui déterminent avant tout la spécificité d'hôte d'un virus donné. Il existe des sondes moléculaires spécifiques des virus écotropiques et xénotropiques, constituées de fragments d'ADN codant pour une partie des glycoprotéines de l'enveloppe des virus écotropiques et xénotropiques respectivement.

Ces sondes moléculaires ont permis de préciser la nature et le nombre des provirus MuLV endogènes présents dans le génome des différentes lignées consanguines de souris (figure 2). Ainsi, l'on a pu montrer que toutes les lignées consanguines de souris (les lignées non leucémiques tout comme les lignées leucémiques) possèdent des provirus endogènes MuLV xénotropiques: 18 à 28 provirus MuLV xénotropiques sont ainsi détectés dans le génome des différentes lignées consanguines. Cinq de ces provirus sont communs à toutes les lignées consanguines de souris. De plus chacune des lignées de souris possède des provirus xénotropiques qui lui sont propres [21].

Si l'on hybride l'ADN des souris 


\section{RÉFÉRENCES}

15. Jaenisch R. Germ line integration and Mendelian transmission of the exogenous Moloney leukemia virus. Proc Natl Acad Sci USA 1976 ; 73 : 1260-4.

16. Gross L. Spontaneous leukemia developing in $\mathrm{C} 3 \mathrm{H}$ mice following inoculation in infancy with Ak-leukemic extracts, or Akembryos. Proc Soc Exp Med 1951 ; 76 : 27-32.

17. Moloney JB. Biological studies on a lymphoid leukemia virus extracted from sarcoma S.37. I. Origin and introductory investigations. J Natl Cancer Inst 1960 ; 24 : 933-51.

18. Friend C. Cell-free transmission in adult Swiss mice of a disease having the character of a leukemia. J Exp Med 1957 ; 105 : 307-18.

19. Taylor BA, Meier H, Myers DD. Hostgene control of C-type RNA tumour virus : inheritance of the group-specific antigen of murine leukemia virus. Proc Natl Acad Sci USA 1971 ; 68 : 3190-4.

20. Rasheed S, Gardner MB, ChanE. Amphotropic host range of naturally occuring wild mouse leukemia viruses. J Virol $1976 ; 19: 13-8$

21. Hoggan MD, Buckler CE, Sears JF, Rowe WP, Martin MA. Organization and stability of endogenous xenotropic murine leukemia virus proviral DNA in mouse genomes. J Virol 1983 ; 45 : 473-7.

22. Jenkins $\mathbf{N}$, Copeland $\mathbf{N}$, Taylor BA, Lee BK. Organization, distribution, and stability of endogenous ecotropic murine leukemia virus DNA sequences in chromosomes of Mus musculus. J Virol 1982 ; 43 : 26-36.

23. Rinchik EM, Russell LB, Copeland NC, Jenkins NA. Molecular genetic analysis of the dilute-short ear (D-SE) region of the mouse. Genetics 1986 ; 112 : 321-42.

24. Lovett M, Epstein C. The lethal yellow allele-associated provirus results in the production of chimeric viral-host RNAs. Proc Natl Acad Sci USA 1987 ; 84 : 2853-7.

25. LohlerJR, TimplR, Jaenisch R. Embryonic lethal mutation in mouse collagen I gene causes rupture of blood vessels and is associated with erythropoietic and mesenchymal death. Cell $1984 ; 38$ : 597-605.

26. Soriano P, Gridley T, Jaenisch R. Retroviruses and insertion mutagenesis in mice : proviral integration at the Mov 34 locus leads to early embryonic death. Genes Dev $1987 ; 1$ : 366-75.

27. Kuehn MR, Bradley A, Robertson EJ, Evans MJ. A potential animal model for Lesch-Nyhan syndrome through introduction of HPRT mutations into mice. Nature $1987 ; 326: 295-8$ consanguines avec la sonde écotropique, on observe de grandes variations d'une lignée murine à l'autre. Toutes les lignées leucémiques possèdent un ou deux provirus MuLV écotropiques qui ont été associés à l'apparition de la maladie. En revanche, certaines lignées de souris (non leucémiques) ne possèdent pas de provirus MuLV écotropique. Au total 29 provirus MuLV écotropiques endogènes répartis dans les 54 lignées consanguines de souris analysées ont été détectés [22]. Le nombre de provirus contenus dans le génome d'une lignée consanguine de souris varie de zéro à six. La plupart des provirus MuLV écotropiques endogènes que l'on repère par hybridation moléculaire peuvent être exprimés sous la forme de particules virales infectieuses, mais certains de ces provirus portent des mutations ponctuelles, des délétions ou des substitutions et ne peuvent pas produire de virus infectieux.

Deux mutations anciennes de la souris ont été associées à l'insertion d'un provirus MuLV écotropique: la mutation dilute (d) et la mutation lethal yellow $\left(\mathrm{A}^{y}\right)$ (figure 3$)$. Toutes deux sont des mutations qui affectent en premier lieu la coloration des souris, mais tandis que $\mathrm{d}$ est récessive (les souris $\mathrm{d} / \mathrm{d}$ ont un pelage plus clair, les souris $d /+$ sont de phénotype sauvage), la mutation $\mathrm{A}^{y}$ est dominante. Les souris $A^{y / t}$ sont jaunes et, comme la plupart des mutations dominantes, cette mutation est létale à l'état homozygote : les souris $\mathrm{A}^{\mathrm{y}} / \mathrm{A}^{\mathrm{y}}$ meurent in utero, au moment de l'implantation, probablement du fait d'une anomalie du trophectoderme. Ces deux mutations insertionnelles sont du plus grand intérêt pour les généticiens ; elles ont en effet permis d'entamer l'étude moléculaire de deux régions importantes du génome de la souris : la région dilute-short ear [23] située sur le chromosome 9, et le locus agouti [24], localisé sur le chromosome 2.

\section{Mutagenèse rétrovirale exogène}

Trois mutations résultant d'une infection par un virus exogène ont été décrites. La mutation insertionnelle la mieux caractérisée à ce jour est la mutation Mov 13. Elle a été obtenue par Jaenisch à la suite d'une micro-injection du virus MuLV de Moloney (Mo-MuLV) directement à travers la paroi de l'utérus, dans des

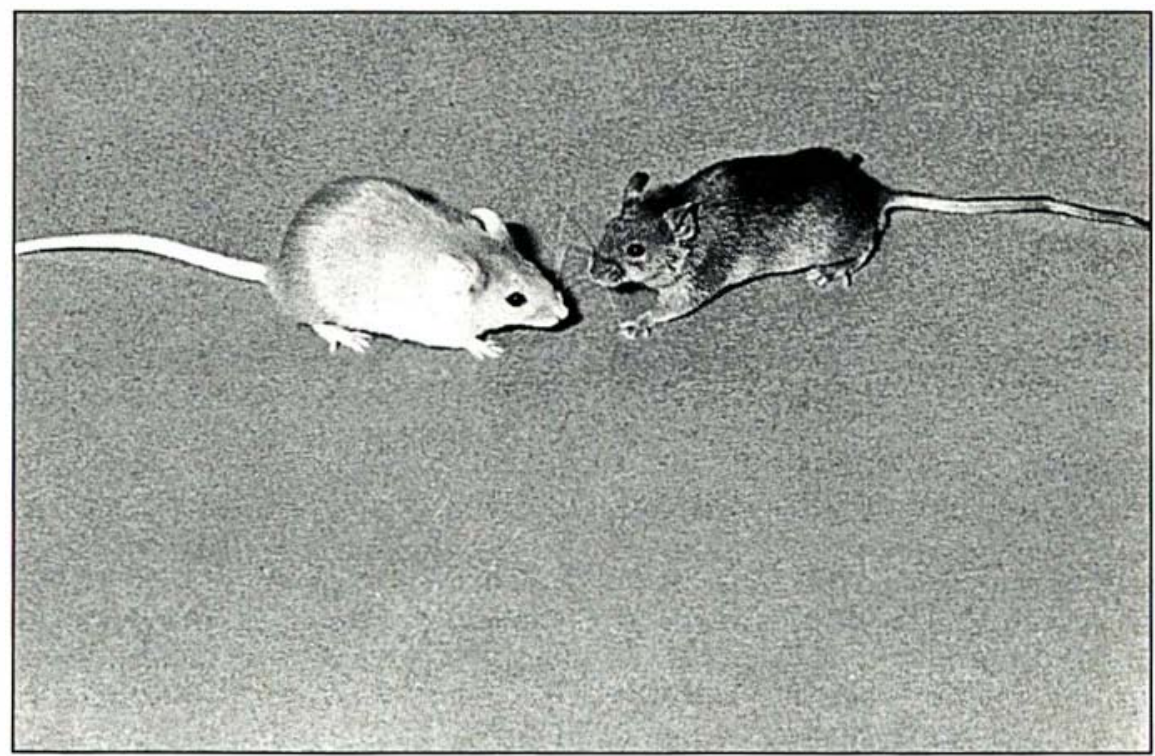

Figure 3. Deux anomalies héréditaires (mutations) de la couleur du pelage de la souris sont associées à la présence de provirus MuLV écotropiques. Dilute, responsable de l'aspect délavé du pelage gris de la première de ces souris et lethal yellow, responsable de la couleur jaune de la seconde. (Cliché J.-L. Guénet.) 


\section{kilobases

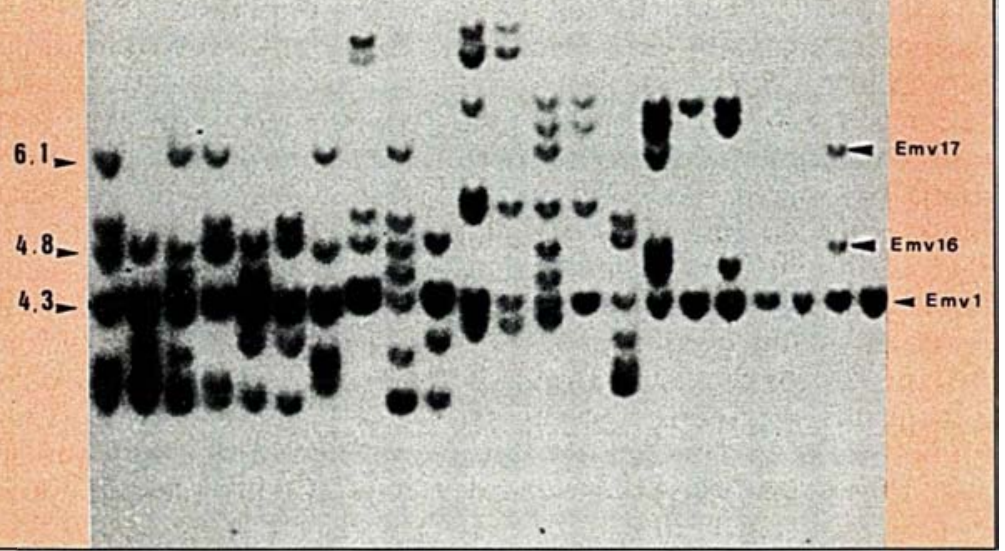

Figure 4. Contenu en provirus MuLV écotropique du génome de 22 souris issues du croisement des lignées SWR/J et RF/J. Les ADN extraits de chacune de ces souris ont été digérés par Pvull (voir figure 2), fractionnés sur un gel d'agarose, transférés sur un filtre où ils ont été hybridés avec la sonde ENV spécifique des virus MuLV écotropiques. Chaque bande correspond à un provirus donné. Si les souris 19, 20, 21 et 22 ne portent que les provirus hérités de leurs parents (ces provirus parentaux, signalés par des flèches, ont été baptisés Emv1, Emv16 et Emv17), en revanche les autres souris, 1 à 18 comprises, ont acquis en plus de nouveaux provirus MuLV écotropiques.

embryons au jour 8 de la gestation. Les souris homozygotes Mov 13/ Mov 13 meurent au jour 13 de la gestation. Il a été montré que le provirus s'est intégré dans le premier intron du gène codant pour l'al (I) collagène. Les souris homozygotes pour cette insertion voient leur développement cesser au jour 12, à la suite d'une nécrose progressive des cellules mésenchymateuses et érythropoïétiques, qui est suivie d'une rupture des vaisseaux sanguins les plus importants [25].

La mutation Mov 34 résulte de l'infection par le virus Mo-MuLV d'embryons de souris au stade 4-16 cellules. Les souris homozygotes Mov 34/Mov 34 meurent peu après l'implantation, au jour 6 de la gestation. Les premières analyses moléculaires du site d'insertion suggèrent que: (a) le provirus s'est intégré en amont d'un gène exprimé à des niveaux similaires dans tous les tissus de l'embryon de dix jours, et (b) l'insertion du provirus au locus $\mathrm{m} / \mathrm{s} n^{\circ} 9$ vol. 4, novembre 88 rêt que peut présenter l'utilisation de la mutagenèse insertionnelle chez la souris.

\section{La mutagenèse insertionnelle endogène}

En 1985, Jenkins et Copeland rapportent une observation curieuse: certaines souris hybrides issues du croisement de deux lignées consanguines de souris, les lignées $\mathrm{RF} / \mathrm{J}$ et $\mathrm{SWR} / \mathrm{J}$, acquièrent des provirus MuLV écotropiques que ne possédaient ni l'une ni l'autre des deux lignées parentales (figure 4). De plus les nouveaux provirus sont transmissibles à la descendance [28]. Dès le départ, le phénomène apparaissait vraisemblablement lié à l'infection des embryons, avant ou peu après la fécondation, par un virus écotropique MuLV produit dans les tissus des femelles hybrides SWR/J-RF/J. Récemment, il nous a été possible de valider ce modèle en montrant que l'inoculation d'un MuLV écotropique à des femelles SWR/J nouveaunées (dont le génome n'héberge aucun provirus) aboutit au même résultat. Pour cela, le virus MuLV écotropique exprimé chez les souris hybrides $S W R / J-R F / J$ a été isolé. On peut montrer que : (1) le virus se réplique chez les femelles inoculées ; (2) il infecte préférentiellement les cellules thécales de l'ovaire de ces souris; (3) environ $10 \%$ des souriceaux qui naissent du croisement des femelles inoculées avec un mâle SWR/J sont transgéniques: leurs chromosomes propagent en effet un ou plusieurs provirus MuLV écotropiques; (4) ces nouveaux provirus sont transmissibles à la descendance [29]. Le phénomène d'acquisition de provirus MuLV écotropiques chez les souris hybrides SWR/J$\mathrm{RF} / \mathrm{J}$ est donc lié à une propriété particulière du virus MuLV écotropique exprimé chez les souris hybrides SWR/J-RF/J. L'infection rétrovirale a très probablement lieu pendant l'oogenèse chez les femelles inoculées [30].

Ces observations ouvrent la voie à un type de mutagenèse insertionnelle qui ne devrait plus nécessiter de manipulation d'œufs, d'embryons ou de cellules ES, l'insertion du provirus dans le génome de la souris ayant lieu in vivo. Ces méthodes sont 
RÉFÉRENCES

28. Jenkins NA, Copeland NG. High frequency germ line acquisition of ecotropic MuLV in SWR/J-RF/J hybrid mice. Cell $1985 ; 43$ : $811-9$.

29. Panthier JJ, Condamine H, Jacob F. Inoculation of newborn $S W R / J$ females with an ecotropic murine leukemia virus can produce transgenic mice. Proc Natl Acad Sci USA $1988 ; 85$ : 1156-60.

30. Panthier JJ, Condamine H. Expression of ecotropic MuLV in ovaries of SWR/J$\mathrm{RF} / \mathrm{J}$ hybrid mice. Ann Inst Pasteur Virol 1987 ; $138:$ 409-22.

31. Hayward WS, Neel BG, Astrin SM. Activation of a cellular oncogene by promoter insertion in ALV-induced lymphoid leukosis. Nature 1981 ; 290 : 475-80.

32. Nusse $\mathbf{R}$. The activation of cellular oncogenes by retroviral insertion. Trends Genet $1986 ; 2: 244-7$.

33. Corcoran LM, Adams JM, Dunn AR, Cory S. Murine T lymphomas in which the cellular myc oncogene has been activated by retroviral insertion. Cell 1984; $37: 113-22$.

34. Selten G, Cuypers HT, Boelens W, et al. The primary structure of the putative oncogene pim-l shows extensive homology with protein kinases. Cell 1986; 46 : 603-11.

35. Shen-Ong GLC, Morse III HC, Potter M, Mushinski F. Two modes of c-myb activation in virus-induced mouse myeloid tumors. $\mathrm{Mol}$ Cell Biol 1986; 6 : 380-92.

36. Hartley JW, Wolford NK, OldLJ, Rowe WP. A new class of murine leukemia virus associated with development of spontaneous lymphomas. Proc Natl Acad Sci USA $1977 ; 74: 789-92$.

37. Chattoppadhyay SK, Cloyd MW, Linemeyer DL, Lander MR, Rands E, Lowy DR. Cellular origin and role of mink cell focusforming viruses in murine thymic lymphomas. Nature $1982 ; 295$ : 25-31.

38. Vijaya S, Steffen DL, Robinson HL. Acceptor sites for retroviral integrations map near DNasel-Hypersensitive sites in chromatin. J Virol 1986; 60 : 683-92.

39. Rohdewohld H, Weiher H, Reik W, Jaenisch R, Breindl M. Retroviral integration and chromatin structure: Moloney murine leukemia proviral integration sites map near DNase I-Hypersensitive sites. J Virol 1987 ; 61 : 336-43.

40. Thomas KR, Capecchi MR. Site-directed mutagenesis by gene targeting in mouse embryo-derived stem cells. Cell 1987; 51 : récentes et aucun mutant ainsi obtenu n'a pour l'instant été décrit.

\section{La leucémogenèse}

En 1981, Hayward et al. [31] ont montré que dans la majorité des lymphomes induits par le virus leucémogène aviaire $(\mathrm{ALV})$ le génome viral est intégré, sous la forme d'un provirus, en amont de l'oncogène cellulaire $c-m y c$. Dans ces tumeurs, la transcription du gène $c-m y c$ est 30 à 100 fois plus élevée que dans le tissu sain et un messager hybride, spécifique de ces cellules transformées, comprenant des séquences virales associées à des séquences $c-m y c$ est synthétisé. Le gène $c-m y c$ est ainsi passé sous le contrôle des séquences régulatrices (LTR, long terminal repeat) virales. Depuis cette découverte, un nombre croissant de résultats ont confirmé l'hypothèse que les leucémies induites par les virus transformants lents (ALV ou MuLV) résultent de mutations insertionnelles qui se produisent dans les cellules des lignées hématopoïétiques. Les virus MuLV agissent, tout comme le virus $A L V$, en s'insérant au voisinage de proto-oncogènes cellulaires dont ils activent l'expression. L'activation de l'oncogène peut être due à l'insertion du LTR d'un provirus défectif en amont du gène ou à l'insertion d'un provirus intact en aval ou à l'intérieur même des séquences de l'oncogène [32].

Chez la souris, une dizaine d'oncogènes présomptifs ou connus pour leurs propriétés transformantes sont impliqués dans les lymphomes de type $\mathrm{T}$ d'origine rétrovirale : ce sont par exemple c-myc [33], pim-1 [34], ainsi que, dans les tumeurs myéloïdes, $m y b$ [35]. Toutefois, la leucémogenèse murine semble dans beaucoup de cas résulter d'un processus plus complexe que la simple insertion d'un MuLV écotropique au voisinage ou à l'intérieur d'un protooncogène cellulaire. Un ou plusieurs événements de recombinaison peuvent être mis en jeu entre les séquences MuLV écotropiques et des virus non écotropiques, probablement distincts des provirus xénotropiques, mais non encore identifiés [36, 37]. Ce sont en effet de tels virus recombinants (baptisés MCF pour mink cell focus-inducing viruses, en raison des changements morphologiques caractéristiques que ces virus provoquent in vitro sur les cellules de vison) que l'on retrouve souvent insérés dans les régions adjacentes des différents oncogènes cellulaires impliqués.

En conclusion, l'analyse des séquences de nucléotides aux jonctions virus-ADN cellulaire de différents sites d'intégration n'a pas mis en évidence, jusqu'à présent, de séquence consensus pour l'intégration des rétrovirus. Il semble cependant que l'intégration des rétrovirus ne se fasse pas au hasard, mais qu'elle ait préférentiellement lieu dans des régions de l'ADN hypersensibles à un traitement par la désoxyribonucléase $1[38$, 39]. De telles régions « ouvertes» de la chromatine sont présentes en amont des gènes exprimés. Ces résultats suggèrent que le gène muté (où s'est inséré le rétrovirus) sera préférentiellement un gène exprimé au moment de l'intégration. L'on ne peut s'empêcher de remarquer que Mov 13 (qui résulte d'une infection au jour 8) est situé dans un gène exprimé à partir du jour 8 , tandis que Mov 34 (qui résulte d'une infection au jour 3) est localisé dans un gène probablement exprimé de façon ubiquitaire à partir du jour 4 .

Il reste que quel que soit le mode de mutagenèse insertionnelle retenu, aucun ne permet actuellement de «cibler » les mutations dans un gène choisi à l'avance avec une grande efficacité. Mais on a une idée des fréquences relatives d'intégration d'une séquence exogène, «au hasard » d'une part, dans un site homologue (à supposer qu'il en existe un) d'autre part, grâce notamment à des données publiées par Thomas et Capecchi [40]. Ces auteurs ont transfecté des cellules ES avec l'ADN d'un plasmide comportant un gène bactérien de résistance à la néomycine placé à l'intérieur du gène murin de l'HPRT. Le «truc» est ici que toute insertion de cet $\mathrm{ADN}$ exogène qui se produit, par recombinaison homologue, dans le gène HPRT de la cellule hôte entraîne l'apparition d'une mutation $\mathrm{HPRT}^{-}$puisque la séquence HPRT exogène a été mutée par l'insertion du gène de résistance à la néomycine. Or les mutants HPR T ${ }^{-}$peuvent être sélectionnés directement par leur résistance à la 6-thioguanine. 
Thomas et Capecchi ont donc pu établir le rapport du nombre de transfectants résistants à la fois à la néomycine et à la 6-thioguanine (qui résultent d'une insertion au site homologue) au nombre de transfectants résistants à la seule néomycine (qui proviennent d'une insertion en un site quelconque). Ce rapport, dans les meilleurs cas, est de $10^{-3}$ (il augmente avec la longueur de la séquence homologue exogène). Comme on ne dispose de technique de sélection pour aucun gène de développement connu, on voit qu'on doit récolter $10^{3}$ mutants insertionnels pour en trouver en moyenne un qui affectera un gène donné à l'avance, homologue d'un fragment de la séquence exogène. L'intérêt des cellules ES est qu'elles permettent (peut-être) de jouer une telle partie, ce que ne permet sûrement pas la technique d'injection de l'ADN dans l'œuf. Quant à la mutagenèse rétrovirale, s'il est vrai qu'elle met en jeu des mécanismes d'intégration propres aux rétrovirus, elle ne pourra sans doute jamais être utilisée pour cibler les mutations par recombinaison homologue. Son intérêt majeur, outre la simplicité des manipulations qu'elle implique (surtout dans le cas des souris $S W R / J$ ) réside dans la structure très simple des insertions auxquelles elle donne lieu, comparées aux insertions de séquences injectées dans l'œuf.

Chez la souris, un nombre sans cesse croissant de gènes sont identifiés, dont tout indique qu'ils ont un rôle important dans le développement de l'embryon: oncogènes cellulaires, gènes codant pour des facteurs de croissance ou leur récepteur, « homéogènes » repérés par la présence dans un exon d'une «boîte homéo » possédant un haut degré d'homologie avec celle des gènes homéotiques de la drosophile. L'obtention systématique de mutants récessifs, correspondant à une abolition au moins partielle de la fonction de ces gènes, serait extrêmement précieuse pour préciser celle-ci. Il est clair que les techniques de mutagenèse insertionnelle devront encore être améliorées pour parvenir à un tel objectif mais, telles quelles, elles peuvent contribuer beaucoup au progrès de la génétique moléculaire chez la souris

$\mathrm{m} / \mathrm{s}$ no 9 vol. 4 , novembre 88

\section{Summary}

Insertional mutagenesis results from the insertion of a foreign DNA sequence into the DNA of a host cell. Provided that the inserted piece is available as a cloned DNA molecule, such a mutation will make possible the isolation and cloning of the mutated gene sequences flanking the insert. Various aspects of insertional mutagenesis in mice are reviewed. Insertion of foreign DNA in the genome of early embryonic cells can result from the injection of linear DNA molecules into the fertilized egg or from in vitro transfection of embryonal stem cells. A number of mutants of developmental interest obtained in this way have been described. Alternatively, the properties of ecotropic MuLV, a murine retrovirus which can be stably propagated as an integrated provirus, have been also used. The insertional mutations obtained so far in this way result from the exogenous infection of (mainly) preimplantation embryos with infectious MuLV particles. However, the introduction of a particular MuLV inside the genome of the SWR/J strain results in the production of spontaneous endogenous mutations, thus representing a potentially useful new source of insertional mutants. Reinsertion of MuLV sequences in the DNA of somatic tissues can also lead to the production of cells with an oncogenic potential, as is well documented with various lymphocytic tumors. Finally, the advantages of the various ways to obtain insertional mutations in mice are compared, both regarding the feasability of homologous recombination experiments and the structure of the insert.

\section{TIRÉS A PART}

J.-J. Panthier. 